\title{
Sum of Diameters
}

National Cancer Institute

\section{Source}

National Cancer Institute. Sum of Diameters. NCI Thesaurus. Code C96631.

A calculation of the aggreg ated diameter values. 